\title{
Qualifier Evaluator
}

National Cancer Institute

\section{Source}

National Cancer Institute. Qualifier Evaluator. NCI Thesaurus. Code C83363.

A person who determines the significance of a qualifier. 